\title{
Clozapine Reverses Hyperthermia and Sympathetically Mediated Cutaneous Vasoconstriction Induced by 3,4-Methylenedioxymethamphetamine (Ecstasy) in Rabbits and Rats
}

\author{
W. W. Blessing, B. Seaman, N. P. Pedersen, and Y. Ootsuka \\ Centre for Neuroscience, Departments of Medicine and Physiology, Flinders University, Bedford Park, South Australia 5042, Australia
}

Life-threatening hyperthermia occurs in some individuals taking 3,4-methylenedioxymethamphetamine (MDMA, ecstasy). In rabbits, sympathetically mediated vasoconstriction in heat-exchanging cutaneous beds (ear pinnae) contributes to MDMA-elicited hyperthermia. We investigated whether MDMA-elicited cutaneous vasoconstriction and hyperthermia are reversed by clozapine and olanzapine, atypical antipsychotic agents. Ear pinna blood flow and body temperature were measured in conscious rabbits; MDMA (6 mg/kg, i.v.) was administered; and clozapine ( $0.1-5 \mathrm{mg} / \mathrm{kg}$, i.v.) or olanzapine $(0.5 \mathrm{mg} / \mathrm{kg}$, i.v. $)$ was administered $15 \mathrm{~min}$ later. One hour after MDMA, temperature was $38.7 \pm 0.5^{\circ} \mathrm{C}$ in $5 \mathrm{mg} / \mathrm{kg}$ clozapine-treated rabbits and $39.0 \pm 0.2^{\circ} \mathrm{C}$ in olanzapine-treated rabbits, less than untreated animals $\left(41.5 \pm 0.3^{\circ} \mathrm{C}\right)$ and unchanged from pre-MDMA values. Ear pinna blood flow increased from the MDMA-induced near zero level within $5 \mathrm{~min}$ of clozapine or olanzapine administration. Clozapine-induced temperature and flow responses were dose-dependent. In urethane-anesthetized rabbits, MDMA (6 mg/kg, i.v.) increased ear pinna postganglionic sympathetic nerve discharge to $217 \pm 33 \%$ of the pre-MDMA baseline. Five minutes after clozapine $(1 \mathrm{mg} / \mathrm{kg}$, i.v.) discharge was reduced to $10 \pm 4 \%$ of the MDMA-elicited level. In conscious rats made hyperthermic by MDMA $\left(10 \mathrm{mg} / \mathrm{kg}\right.$, s.c.), body temperature $1 \mathrm{hr}$ after clozapine $\left(3 \mathrm{mg} / \mathrm{kg}\right.$, s.c.) was $36.9 \pm 0.5^{\circ} \mathrm{C}$, $<38.6 \pm 0.3^{\circ} \mathrm{C}$ (Ringer's solution-treated) and not different from the pre-MDMA level. One hour after clozapine, rat tail blood flow was $24 \pm 3 \mathrm{~cm} / \mathrm{sec}$, greater than both flow in Ringer's solution-treated rats $(8 \pm 1 \mathrm{~cm} / \mathrm{sec})$ and the pre-MDMA level $(17 \pm 1 \mathrm{~cm} / \mathrm{sec})$. Clozapine and olanzapine, by interactions with 5 -HT receptors or by other mechanisms, could reverse potentially fatal hyperthermia and cutaneous vasoconstriction occurring in some humans after ingestion of MDMA.

Key words: cutaneous blood flow; cutaneous sympathetic nerve activity; serotonin; 5-HT1A receptors; 5-HT2A receptors; hallucinations; hyperthermia; body temperature; olanzapine; atypical antipsychotic agents

\begin{abstract}
Introduction
Life-threatening and sometimes fatal hyperthermia occurs in some individuals taking 3,4-methylenedioxymethamphetamine (MDMA, ecstasy) or related drugs (Callaway and Clark, 1994; Milroy, 1999; Teter and Guthrie, 2001). MDMA is commonly used, especially by young people, so continuing morbidity and mortality are to be expected. Given that MDMA is illegal in most countries and that its experimental administration to humans is ethically questionable because of possible long-term neurotoxic effects (Green and Goodwin, 1996), animal models of MDMArelated hyperthermia and its treatment must be a high priority.

Recently we demonstrated in rabbits that MDMA-elicited hyperthermia is preceded and accompanied by intense vasocon-
\end{abstract}

\footnotetext{
Received Jan. 2, 2003; revised May 6, 2003; accepted May 7, 2003.

This work was supported by the National Health and Medical Research Council. We thank Kate Barber, Melissa Blair, and Robyn Flook for technical assistance and Dr. Eugene Nalivaiko and Dr. Sue $0^{\prime} B$ Bien for constructive criticism of this manuscript.

Correspondence should be addressed to Dr. W. Blessing, Department of Medicine, Flinders Medical Centre, Bedford Park, South Australia 5042, Australia. E-mail; w.w.blessing@flinders.edu.au.

Copyright $\odot 2003$ Society for Neuroscience $\quad 0270-6474 / 03 / 236385-07 \$ 15.00 / 0$
}

striction in the ear pinnae, the principal heat-exchanging cutaneous bed in this species (Pedersen and Blessing, 2001). Interruption of the sympathetic innervation of one ear pinna substantially reduced the effects of MDMA on both cutaneous vasoconstriction and body temperature. Thus, an MDMAelicited increase in sympathetic discharge to the cutaneous vascular bed contributes to the hyperthermia by reducing the animal's ability to dissipate heat through the skin. In humans with MDMA-elicited hyperthermia, application of cooling agents to the skin is an important component of treatment, and this procedure is less likely to be effective in the face of cutaneous vasoconstriction (Bodenham and Mallick, 1996). Specific treatment of MDMA-elicited hyperthermia with a pharmacological agent that increases cutaneous blood flow would be valuable. A rapid increase in cutaneous blood flow would help determine the temperature-lowering dose in individual hyperthermic patients. Cutaneous blood flow can readily be measured in the human finger with laser Doppler or infrared flowmeters.

In pilot studies, we screened a number of pharmacological agents to determine whether they would reverse MDMA-elicited cutaneous vasoconstriction and hyperthermia in rabbits. We 
now present evidence that clozapine, the first atypical antipsychotic agent (Baldessarini and Frankenburg, 1991) and olanzapine, a closely related antipsychotic drug (Arnt and Skarsfeldt, 1998) reverse sympathetically mediated cutaneous vasoconstriction and hyperthermia elicited by MDMA in conscious freely moving rabbits. To verify that cutaneous blood flow effects of MDMA and clozapine are mediated via appropriate changes in the discharge of cutaneous sympathetic nerves, in anesthetized rabbits we measured drug-induced changes in postganglionic sympathetic discharge in axons supplying ear pinna arteries. To provide more evidence that clozapine and olanzapine could be useful for treating MDMA-elicited hyperthermia in humans, we extended our blood flow studies to a second animal species. We measured blood flow in the tail artery (the cutaneous heatexchanging bed) in conscious freely moving rats. We determined whether MDMA-elicited hyperthermia is associated with cutaneous vasoconstriction in this species and whether clozapine also reverses these changes. We believe that our findings are relevant to the clinical management of patients with life-threatening hyperthermia induced by MDMA.

\section{Materials and Methods}

Experimental procedures were approved by the Flinders University Animal Welfare Committee.

Instrumentation for studies in conscious animals. New Zealand White rabbits $(2.5-4.5 \mathrm{~kg})$ and Sprague Dawley rats (300-450 gm) were prepared with chronically implanted Doppler ultrasonic flow probes around the ear pinna artery (rabbits) and around the tail and superior mesenteric arteries (rats) as described by Pedersen and Blessing (2001) and Garcia et al. (2001) and with intraperitoneal telemetric temperature probes (Data Sciences International, St Paul, MN). Animals were housed in the Flinders Medical Centre Animal House. Experiments were performed on conscious unrestrained animals at least 1 week later, with the animals transferred from the animal house to the laboratory on the day of the experiment. Animals were studied in a temperature-controlled cage (rabbits, $26^{\circ} \mathrm{C}$; rats, $26-28^{\circ} \mathrm{C}$ ). The cages were equipped with a swivel device and flexible cable that attached to a socket fixed to the animal's skull so that blood flow recordings could be made while the conscious animal moved freely within the cage.

Data acquisition and statistical analysis for studies in conscious animals. Temperature and Doppler signals were processed (Triton Technology, San Diego, CA) and digitized $(40 \mathrm{~Hz})$ using PowerLab and Chart software (AD Instruments, Sydney, New South Wales, Australia) and a Macintosh computer (Apple Computer, Cupertino, CA). After a $30 \mathrm{~min}$ control recording, MDMA was administered, and after $15 \mathrm{~min}$ in rabbits and $90 \mathrm{~min}$ in rats, clozapine or olanzapine was administered. Effects on blood flow and body temperature were recorded for an additional $45 \mathrm{~min}$ in rabbits and $60 \mathrm{~min}$ in rats.

Data were analyzed with Chart, IgorPro (WaveMetrics, Lake Oswega, OR), and Statview (SAS Institute, Cary, NC) software. Individual $40 \mathrm{~Hz}$ traces were averaged over 1,5 , or $10 \mathrm{~min}$. For each animal in a particular condition, we then obtained an overall mean of the pre-MDMA control period. Group data were analyzed by repeated measures ANOVA, with comparison of post-MDMA injection values with the corresponding control mean. We compared posttreatment temperature and flow values with the corresponding values recorded $15 \mathrm{~min}$ after MDMA in rabbits and 90 min after MDMA in rats and with the overall value of the preMDMA control period. Factorial ANOVA was used to compare corresponding time points in vehicle- and drug-treated animals and to assess the effect of drug dose. Data from anesthetized rabbits were analyzed by repeated measures ANOVA. Fisher's protected least significance difference (PLSD) comparison was used to determine significant differences, with the limit for statistical significance set at the $p=0.05$ level. Regression analysis was used to determine whether temperature and ear pinna blood flow responses to clozapine in rabbits were dose-dependent.

Studies in anesthetized rabbits. Rabbits were anesthetized with urethane (1.5 gm/kg, i.v., infused over $30 \mathrm{~min})$. An endotracheal tube was inserted via a tracheostomy. The trunk fur was shaved, and the trunk was enclosed by an aluminum foil water jacket through which it was possible to perfuse water of different temperatures. Arterial pressure was measured via a catheter placed in a femoral artery, and body temperature was measured via a rectal thermistor. Skin temperature was measured by a thermistor glued to the skin over the rib cage. The rabbit was placed in a Kopf stereotaxic apparatus. For the initial part of the experiment, the rabbit breathed oxygen spontaneously. The core temperature was maintained at $39-40^{\circ} \mathrm{C}$ by perfusing warm water through the water jacket.

A small ( $\sim 0.1$-mm-diameter) nerve trunk was dissected from the central ear branch of the posterior auricular artery $\sim 3 \mathrm{~cm}$ from the base of the ear (Ootsuka et al., 2002). The distal end of the nerve was cut, and the nerve was placed over bipolar silver-silver chloride wire electrodes. Multiunit nerve action potential recordings were made using a Neurolog NL100 preamplifier and Neurolog NL104 amplifier (filters, 100-1000 $\mathrm{Hz}$; Digitimer Ltd., Hertfordshire, UK). The raw nerve signal was recorded on videotape. A Grass 7P10B signal-conditioning unit (Grass Telefactor, West Warwick, RI), was used to full wave rectify the raw nerve signal bursts that exceeded the noise level, and the suprathreshold signal was integrated with a Neurolog NL705 amplifier (root mean square; time constant, $500 \mathrm{msec}$ ). The processed integrated nerve activity signal and arterial pressure, core body temperature, skin temperature, and end-tidal $\mathrm{CO}_{2}$, measured with a Normocap $\mathrm{CO}_{2}$ monitor (Datex, Helsinki, Finland), were digitized with PowerLab $(100 \mathrm{~Hz})$ and displayed on a Macintosh computer. Integrated nerve activity was analyzed with Chart and IgorPro software.

When stable nerve recordings were obtained, we perfused cold water $\left(10^{\circ} \mathrm{C}\right)$ through the water jacket, causing skin and body temperature to fall. We verified that this procedure increased the amplitude of the integrated nerve activity, thereby confirming the activity as sympathetic in origin, as previously documented for the tail artery nerve in rats (Owens et al., 2002). The animal was then rewarmed. When nerve activity was again stable, the animal was paralyzed (vecuronium bromide, $1 \mathrm{mg} / \mathrm{kg}$ ) and mechanically ventilated so that end-tidal $\mathrm{CO}_{2}$ was $30-35 \mathrm{mmHg}$. When nerve activity had restabilized, we administered MDMA $(6 \mathrm{mg} / \mathrm{kg}$ in $2 \mathrm{ml}$ of Ringer's solution, infused into a femoral vein over $\sim 90 \mathrm{sec}$ ). After 15-30 min, we administered $0.1 \mathrm{mg} / \mathrm{kg}$ clozapine and then, after 5 $\mathrm{min}, 1 \mathrm{mg} / \mathrm{kg}$ clozapine. In some animals, a further $0.5 \mathrm{mg} / \mathrm{kg}$ dose was administered some minutes later. Nerve activity was monitored for another 15-30 min. At the end of the experiment, we administered chlorisondamine $(0.5 \mathrm{mg} / \mathrm{kg})$ to eliminate nerve activity, thus verifying the postganglionic sympathetic nerve origin of our recording and confirming the noise level. Mean levels of nerve activity (2 min samples) after cooling, after administration of MDMA, and after clozapine were compared with the appropriate baseline level using ANOVA with repeated measures.

Drugs and doses. Racemic MDMA (Australian Government Analytical Laboratories, Sydney, Australia) was dissolved in Ringer's solution. Clozapine (ampoules of $50 \mathrm{mg} / 2 \mathrm{ml}$ ) was kindly supplied by Novartis Pharmaceuticals (Sydney, Australia). Olanzapine (kindly supplied by Eli Lilly and Co., Indianapolis, IN) was dissolved in acidified Ringer's solution and dimethylsulfoxide. In rabbits, drugs were administered intravenously. In rats, drugs were administered subcutaneously. We previously showed that $6 \mathrm{mg} / \mathrm{kg}$ intravenous MDMA is a high dose for rabbits, causing hyperthermia-related death in some animals (Pedersen and Blessing, 2001), and we used this dose for rabbits in the present experiments. MDMA at $10 \mathrm{mg} / \mathrm{kg}$ subcutaneously is a moderate hyperthermic dose in rats (Nash et al., 1988b; Gordon et al., 1991; Dafters, 1995; Mechan et al., 2002). Doses for clozapine (0.1-5 mg/kg) and olanzapine $(0.5 \mathrm{mg} / \mathrm{kg})$ were determined by pilot experiments and according to the methods of Nash et al. (1988a).

\section{Results \\ Ear pinna blood flow and body temperature in conscious rabbits}

MDMA gradually increased body temperature and rapidly reduced ear pinna blood flow in rabbits (Figs. 1A, 2). In rabbits given MDMA (6 mg/kg) but no subsequent active drug treat- 

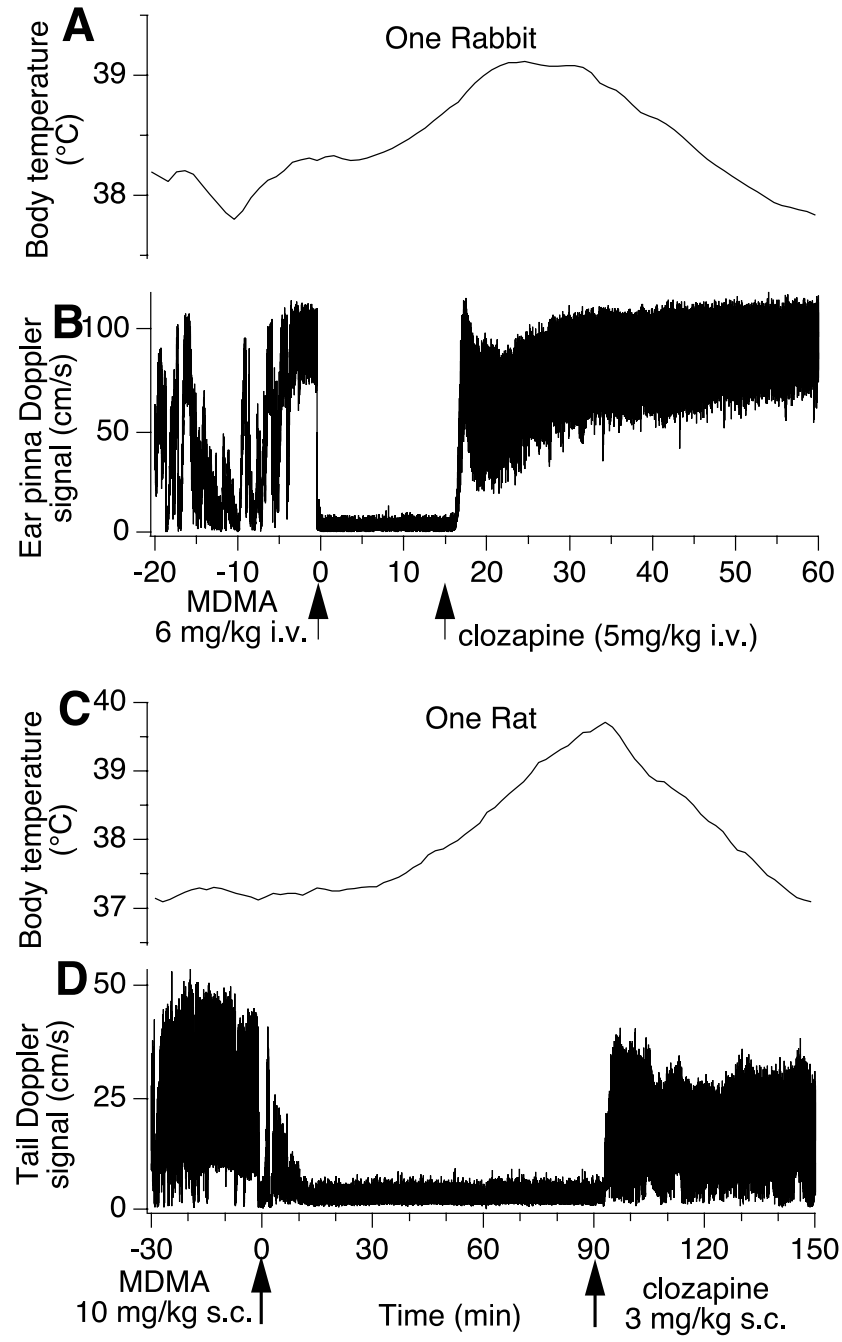

Figure 1. Effect of MDMA and then clozapine on body temperature and cutaneous blood flow in one rabbit $(A, B$, intravenous injection of drugs) and in one rat $(C, D$, subcutaneous injection of drugs). The traces are continuously recorded Doppler ear pinna (rabbit) and tail (rat) signals and telemetrically measured continuously recorded intraperitoneal temperature signals. In both species, administration of MDMA causes intense cutaneous vasoconstriction and increase in body temperature. Both of these effects are reversed by subsequent administration of clozapine.

ment, body temperature increased from $38.3 \pm 0.1$ to $41.3 \pm$ $0.1^{\circ} \mathrm{C}$ measured $45 \mathrm{~min}$ after MDMA; ear pinna blood flow decreased from $28 \pm 2$ to $3 \pm 2 \mathrm{~cm} / \mathrm{sec}$ measured $15 \mathrm{~min}$ after MDMA (nine rabbits studied on 13 occasions; $p<0.01$, repeated measures ANOVA; Fig. $2 A, B$; data from some of these rabbits were previously been published by Pedersen and Blessing, 2001). The severe hyperthermia induced by MDMA clearly distressed some animals. Two animals with temperatures of 43.1 and $43.5^{\circ} \mathrm{C}$ at $45 \mathrm{~min}$ after MDMA lost motor coordination (one convulsed), became cyanosed, and were killed to prevent further distress.

Low-dose clozapine $(0.1$ or $0.5 \mathrm{mg} / \mathrm{kg})$ did not substantially reduce the hyperthermia elicited by MDMA, and some of these rabbits died or were killed before the experiment could be completed. The maximum increase in body temperature in MDMAinjected animals treated with $0.5 \mathrm{mg} / \mathrm{kg}$ clozapine $(n=4)$ was $3.8 \pm 0.7^{\circ} \mathrm{C}$, not significantly different from the maximum increase in untreated MDMA-injected animals $\left[F_{(1,12)}=4.26 ; p>\right.$ 0.05, factorial ANOVA]. In some MDMA-treated rabbits, ear pinna blood flow did increase after clozapine at $0.5 \mathrm{mg} / \mathrm{kg}$, but

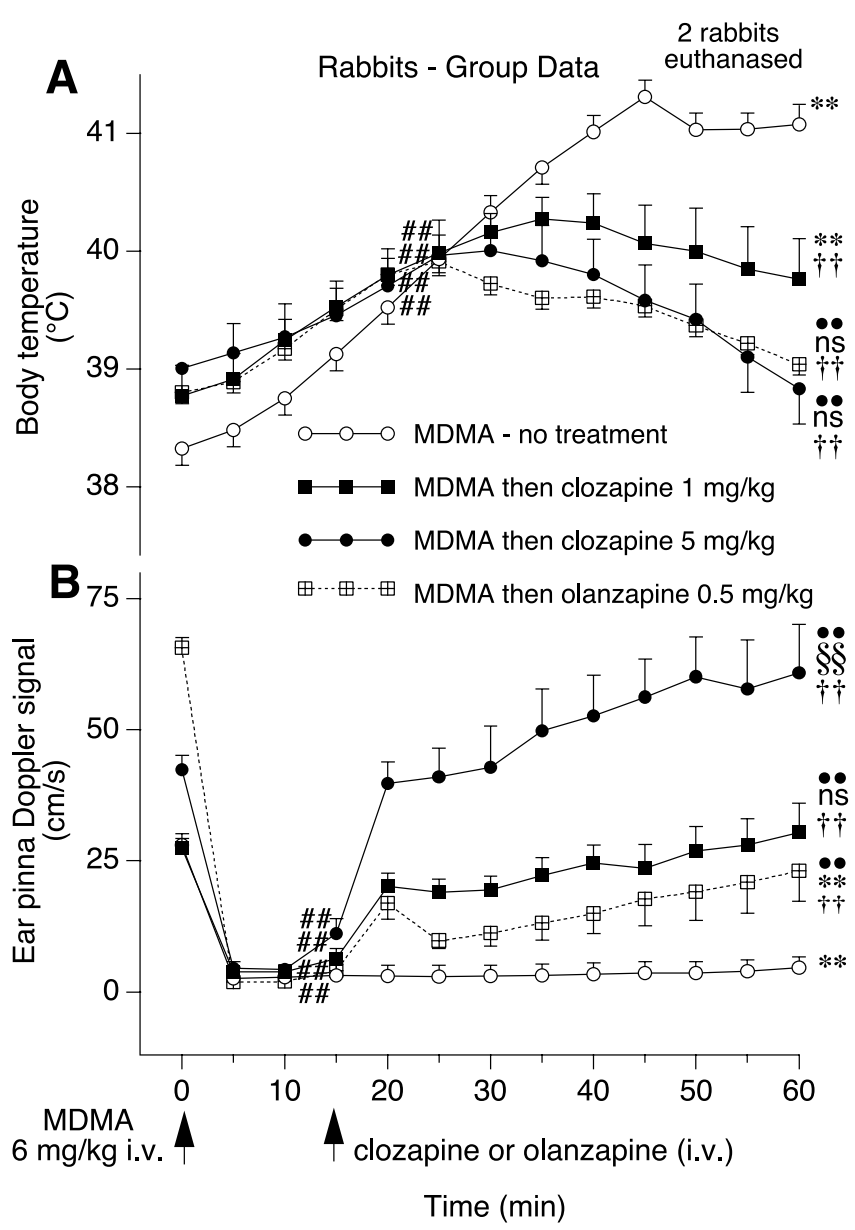

Figure 2. Group data (means and SE) in rabbits showing the effect of intravenous MDMA and then clozapine ( 1 and $5 \mathrm{mg} / \mathrm{kg}$ ) or olanzapine on body temperature $(A)$ and ear pinna blood flow $(B)$. Data points at time 0 are means and SE of the preinjection control period. Two rabbits in the MDMA-no treatment group were killed 45 min after MDMA. Numbers of rabbits: see Results for number of rabbits in MDMA-no treatment group; $n=7$ for clozapine $1 \mathrm{mg} / \mathrm{kg} ; n=$ 5 for clozapine $5 \mathrm{mg} / \mathrm{kg} ; n=6$ for olanzapine $0.5 \mathrm{mg} / \mathrm{kg}$. Symbols for analysis by repeated measures ANOVA and Fisher's PLSD comparison in A: \#\#significantly greater than pre-MDMA control temperature value (no treatment group, $F_{(12,144)}=77.44 ; p<0.0001$; clozapine 1 $\mathrm{mg} / \mathrm{kg}$ group, $F_{(12,60)}=17.61 ; p<0.001$; clozapine $5 \mathrm{mg} / \mathrm{kg}$ group $F_{(12,48)}=3.68 ; p<0.01$; olanzapine group, $\left.F_{(12,60)}=33.48 ; p<0.001\right) ;{ }^{* *}$ significantly greater than pre-MDMA control value ( $F$ values as above; $p<0.0001$ for no treatment group; $p<0.001$ for clozapine $1 \mathrm{mg} / \mathrm{kg}$ group); ${ }^{\bullet \bullet}$ significantly $<30$ min post-MDMA value ( $F$ values as above; $p<0.001$ for clozapine $5 \mathrm{mg} / \mathrm{kg}$ group; $p<0.0001$ for olanzapine group); ns, not significantly different from preMDMA control value ( $F$ values as above; $p>0.05$ for clozapine $5 \mathrm{mg} / \mathrm{kg}$ group; $p>0.05$ for olanzapine group). Symbols for analysis by factorial ANOVA and Fisher's PLSD comparison in $A$ : ${ }^{+{ }^{+}}$significantly $<60$ min post-MDMA temperature in MDMA-no treatment rabbits $\left(F_{(3,26)}=\right.$ 17.503; clozapine $1 \mathrm{mg} / \mathrm{kg}$ group, $p<0.001$; clozapine $5 \mathrm{mg} / \mathrm{kg}$ group, $p<0.0001$; olanzapine group $p<0.0001$ ). Symbols for analysis by repeated measures ANOVA and Fisher's PLSD comparison in $B$ : \#\#significantly less than pre-MDMA ear pinna blood flow control value (no treatment group, $F_{(12,144)}=28.26 ; p<0.0001 ;$ clozapine $1 \mathrm{mg} / \mathrm{kg}$ group, $F_{(12,72)}=13.28$; $p<0.0001$; clozapine $5 \mathrm{mg} / \mathrm{kg}$ group, $F_{(12,48)}=18.29 ; p<0.0001$; olanzapine group, $\left.F_{(12,60)}=14.57 ; p<0.0001\right) ;{ }^{*}$ significantly less than pre-MDMA control value ( $F$ values as above; $p<0.0001$ for no treatment group; $p<0.0001$ for olanzapine group); ${ }^{\S \S}$ significantly greater than pre-MDMA control value ( $F$ values as above; $p<0.01) ;{ }^{\bullet}{ }^{\text {significantly }>15 \mathrm{~min}}$ post-MDMA value ( $F$ values as above; $p<0.0001$ for clozapine $5 \mathrm{mg} / \mathrm{kg}$ group; $p<0.0001$ for clozapine $1 \mathrm{mg} / \mathrm{kg}$ group; $p<0.01$ for olanzapine group); ns, not significantly different from pre-MDMA control value ( $F$ values as above; $p>0.05$ for clozapine $1 \mathrm{mg} / \mathrm{kg}$ group; $p>0.05$ for olanzapine group). Symbols for analysis by factorial ANOVA and Fisher's PLSD comparison in $B$ : ${ }^{+\dagger}$ significantly $>60$ min post-MDMA ear pinna blood flow in MDMA-no treatment rabbits $\left(F_{(3,26)}=17.503\right.$; clozapine $5 \mathrm{mg} / \mathrm{kg}$ group, $p<0.0001$; clozapine $1 \mathrm{mg} / \mathrm{kg}$ group, $p<0.001$; olanzapine group, $p<0.0001)$. 
the effect was quite variable and inconsistent, so statistical analysis was not appropriate.

After clozapine ( $1 \mathrm{mg} / \mathrm{kg}$ administered $15 \mathrm{~min}$ after MDMA), all rabbits remained well. Body temperature $1 \mathrm{hr}$ after MDMA (45 min after clozapine) was less than the corresponding temperature in untreated animals but still greater than the pre-MDMA control value (Fig. $2 A$ ). In these rabbits, ear pinna blood flow rapidly increased after administration of $1 \mathrm{mg} / \mathrm{kg}$ clozapine (Fig. $2 B$ ), with values 5-45 min after clozapine (20-60 min after MDMA) being greater than the preclozapine value recorded 15 min after administration and also reduced the MDMA-provoked rise of body temperature, so that $60 \mathrm{~min}$ after MDMA, body temperature was $38.7 \pm 0.5^{\circ} \mathrm{C}$ in clozapine-treated animals and $39.0 \pm$ $0.2^{\circ} \mathrm{C}$ in olanzapine-treated animals. These temperatures were significantly $<41.5 \pm 0.3^{\circ} \mathrm{C}$, the corresponding temperature 60 min after MDMA in untreated animals, and not significantly different from the pre-MDMA control temperature levels in the same rabbits (Fig. 2A). As determined by repeated measures ANOVA and Fisher's PLSD comparison, ear pinna blood flow increased significantly within $5 \mathrm{~min}$ of administration of $5 \mathrm{mg} / \mathrm{kg}$ clozapine $\left[F_{(12,48)}=18.29 ; p<0.001\right]$ and olanzapine $\left[F_{(12,60)}=\right.$ $14.57 ; p<0.05]$ and remained at a higher level for the duration of the observation period (Fig. $2 \mathrm{~B}$ ). At the $60 \mathrm{~min}$ post-MDMA time point, ear pinna blood flow in rabbits treated with $5 \mathrm{mg} / \mathrm{kg}$ clozapine was significantly higher than the pre-MDMA control blood flow level (Fig, $2 B$ ).

Linear regression analysis yielded a significant inverse relationship between logarithmic doses of clozapine ( 1 and $5 \mathrm{mg} / \mathrm{kg}$ ) and body temperature at the $60 \mathrm{~min}$ post-MDMA time point $\left[F_{(1,9)}=5.26 ; p<0.05\right]$. Similarly, linear regression analysis yielded a significant relationship between logarithmic doses of clozapine ( 1 and $5 \mathrm{mg} / \mathrm{kg}$ ) and the level of blood flow at the 60 min post-MDMA time point $\left[F_{(1,10)}=10.75 ; p<0.01\right]$. The effects of clozapine in reversing MDMA-elicited changes in temperature and ear pinna blood flow were thus dose-dependent.

Ear pinna sympathetic nerve activity and body temperature in anesthetized rabbits

When the trunk skin was cooled, the recorded ear pinna sympathetic nerve activity gradually increased in all five rabbits, so that 5 min after onset of cooling, the integrated nerve activity signal was $154 \pm 14 \%$ of the precooling baseline $\left[F_{(1,4)}=72.19 ; p<\right.$ $0.01]$. MDMA (6 mg/kg, i.v., over $\sim 90 \mathrm{sec})$ increased sympathetic nerve discharge in all five rabbits (Fig. 3A), so that 15-30 min after administration of MDMA, the integrated signal was $217 \pm 33 \%\left[F_{(2,8)}=29.36 ; p<0.01\right]$ of the pre-MDMA baseline level (Fig. $3 A, B$ ). Subsequent administration of $0.1 \mathrm{mg} / \mathrm{kg}$ intravenous clozapine did not change nerve activity (Fig. $3 A, B$ ). Administration of $1 \mathrm{mg} / \mathrm{kg}$ intravenous clozapine promptly and substantially reversed the MDMA-elicited increase in sympathetic nerve discharge (Fig. 3A,B). Within 5 min of administration of this dose of clozapine, the integrated nerve activity signal had fallen to $10 \pm 4 \%$ of the post-MDMA nerve activity values $\left[F_{(2,8)}=29.36 ; p<0.001\right]$ and $26 \pm 14 \%$ of the pre-MDMA baseline values $\left[F_{(2,8)}=29.36 ; p<0.01\right]$.

MDMA increased core body temperature (Fig. 3C) from $38.8 \pm 0.2$ to $39.7 \pm 0.4^{\circ} \mathrm{C}$ within 15 min of administration $\left[F_{(1,4)}\right.$ $=8.87 ; p<0.05]$. MDMA caused a transient rise in arterial pressure (Fig. $3 D$ ), but $15 \mathrm{~min}$ after MDMA, there was no overall significant change in arterial pressure $[102 \pm 7$ and $101 \pm 5$ $\mathrm{mmHg}$ before and after MDMA, respectively; $F_{(2,8)}=22.66 ; p>$ $0.05]$. Clozapine ( $1 \mathrm{mg} / \mathrm{kg}$, i.v.) caused a moderate fall in arterial pressure, so that $5 \mathrm{~min}$ after clozapine, arterial pressure had fallen
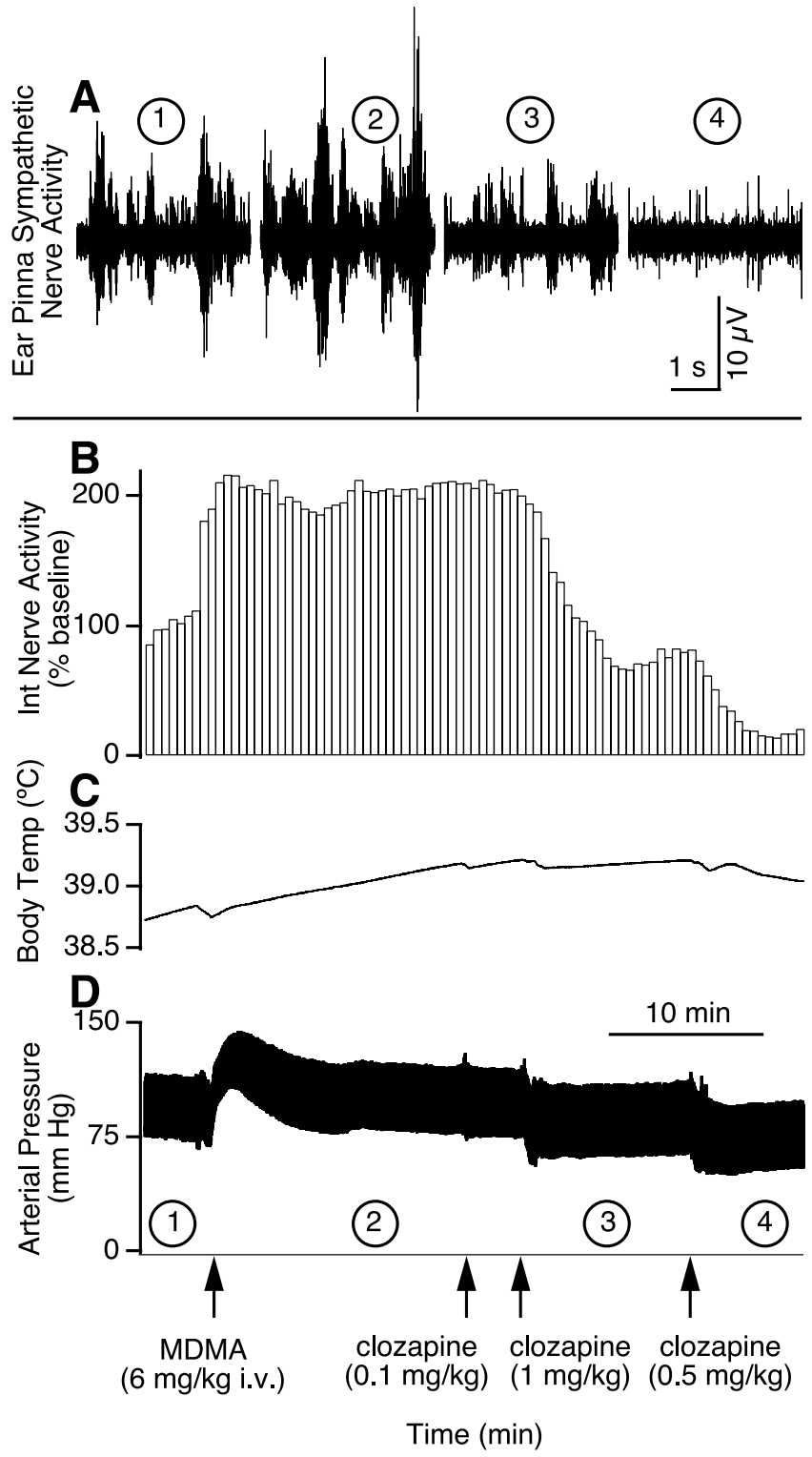

Figure 3. Effect in one anesthetized rabbit of MDMA and then clozapine on ear pinna sympathetic nerve activity $(A)$, integrated (30 sec bins) ear pinna sympathetic nerve activity $(B)$, body temperature $(C)$, and arterial pressure $(D)$. The circled numbers $(1-4)$ in $A$ correspond to the circled numbers on the $x$-axis in $D$, indicating the experimental period during which the nerve recording was made. The $10 \mathrm{~min}$ time base bar in $D$ also applies for $B$ and $C$.

from $102 \pm 7$ (pre-MDMA level) to $72 \pm 6 \mathrm{mmHg}\left[F_{(2,8)}=\right.$ 22.66; $p<0.01]$.

Body temperature and tail artery blood flow in conscious rats MDMA (10 mg/kg) increased body temperature in rats (Figs. $1 C$, $4 A$ ). Ninety minutes after subcutaneous injection of MDMA, body temperature had increased from $37.2 \pm 0.1$ to $38.1 \pm 0.2^{\circ} \mathrm{C}$ in the group to be treated with vehicle and from $36.7 \pm 0.1$ to $38.4 \pm 0.2^{\circ} \mathrm{C}$ in the group to be treated with clozapine (Fig. $4 \mathrm{~A}$ ). At this time, we administered either Ringer's solution $(0.5 \mathrm{ml})$ or clozapine $(3 \mathrm{mg} / \mathrm{kg}$ ) subcutaneously. Clozapine rapidly and substantially decreased body temperature (Figs. $1 C, 4 A$ ), so that 60 min after clozapine, temperature had fallen to $36.9 \pm 0.5^{\circ} \mathrm{C}$, substantially $<38.6 \pm 0.3^{\circ} \mathrm{C}$, the corresponding value in Ringer's solution-treated animals and not significantly different from the pre-MDMA temperature value (Fig. $4 A$ ). 

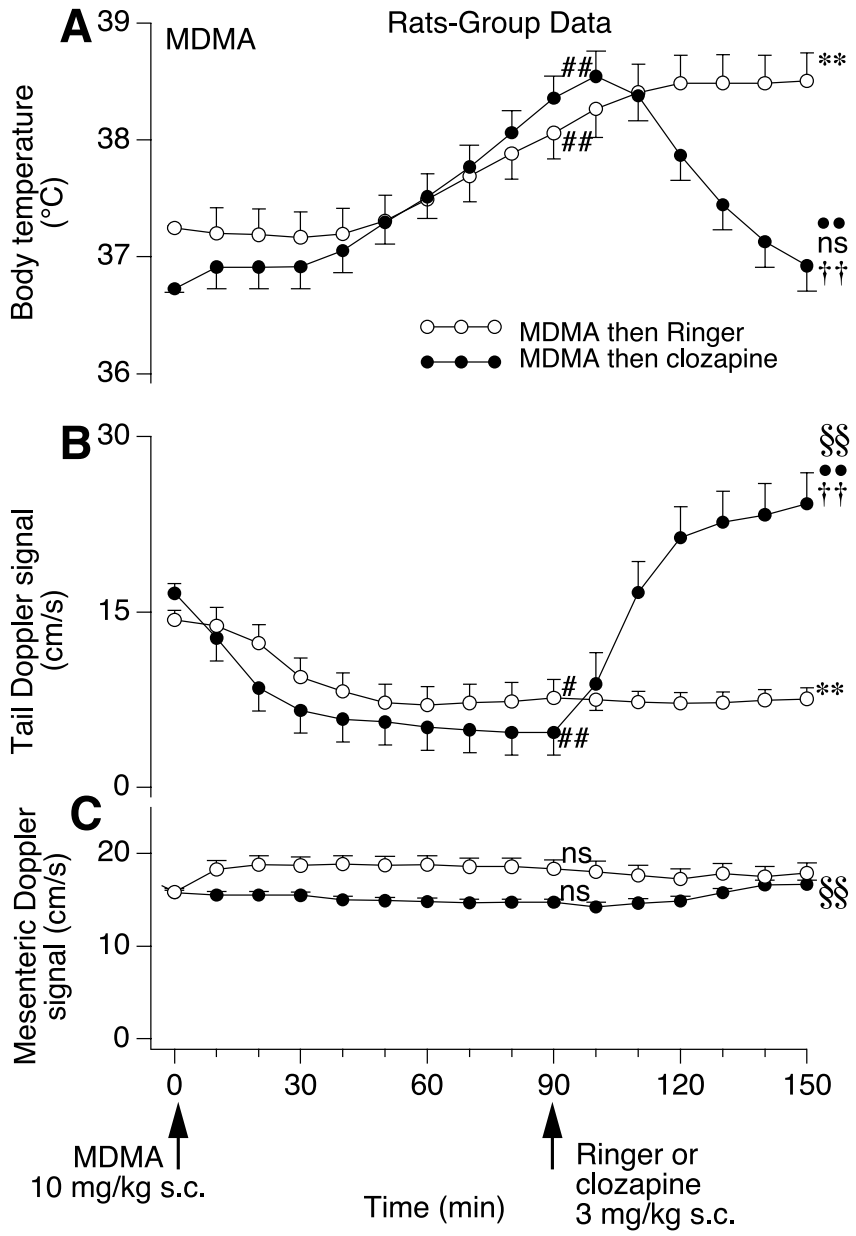

Figure 4. Group data (means and SE) in rats showing effect of subcutaneous MDMA and then Ringer's solution or clozapine on body temperature $(A)$, tail blood flow $(B)$, and superior mesenteric blood flow ( $($ ). Data points at time 0 are means and $S E$ of the preinjection control period. Numbers of rats: $n=6$ for MDMA and Ringer's solution; $n=5$ for MDMA and clozapine for temperature and tail flow studies; $n=4$ for mesenteric flow study. Symbols for analysis by

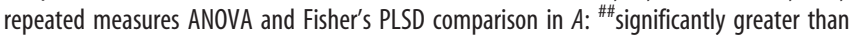
pre-MDMA control temperature (Ringer's solution group, $F_{(15,75)}=15.52 ; p<0.0001$; clozapine group, $\left.F_{(15,60)}=19.82 ; p<0.001\right) ;{ }^{*}$ significantly greater than pre-MDMA control value ( $F$ values as above; $p<0.0001) ;{ }^{\bullet}$ significantly $<100$ min post-MDMA value ( $F$ values as above; $p<0.0001$ ); ns, not significantly different from pre-MDMA control value ( $F$ values as above; $p>0.05$ ). Symbols for analysis by factorial ANOVA and Fisher's PLSD comparison in $A$ : ${ }^{\mathrm{tt}}$ significantly $<150$ min post-MDMA temperature in MDMA and Ringer's solution group $\left[F_{(1,9)}=10.66 ; p<0.01\right)$. Symbols for analysis by repeated measures ANOVA and Fisher's PLSD comparison in $B$ : \#" significantly less than pre-MDMA tail flow (Ringer's solution group, $F_{(15,75)}=3.33 ; p<0.01$; clozapine group, $\left.F_{(15,60)}=16.62 ; p<0.001\right) ;{ }^{* *}$ significantly less

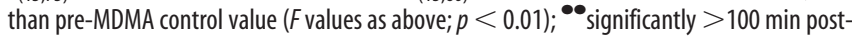
MDMA value ( $F$ values as above; $p<0.0001) ;{ }^{\S \S}$ significantly greater than pre-MDMA control value ( $F$ values as above; $p<0.001$ ). Symbols for analysis by factorial ANOVA and Fisher's PLSD comparison in $B:{ }^{+\dagger}$ significantly $>150$ min post-MDMA tail flow in MDMA and Ringer's solution group $\left(F_{(1,9)}=10.66 ; p<0.01\right)$. Symbols for analysis by repeated measures ANOVA and Fisher's PLSD comparison in C: ns, not significantly different from pre-MDMA mesenteric flow value (Ringer's solution group, $F_{(15,60)}=0.61 ; p>0.05$; clozapine group, $F_{(15,45)}=4.03 ; p>$ $0.05) ;{ }^{\S \S}$ significantly $>90 \mathrm{~min}$ (preclozapine) mesenteric flow value ( $F$ values as above; $p<$ $0.001)$.

MDMA substantially decreased rat tail artery blood flow (Figs. $1 D, 4 B)$. Ninety minutes after injection of MDMA, mean tail artery flow had decreased from $14 \pm 1$ to $8 \pm 2 \mathrm{~cm} / \mathrm{sec}$ in the group to be treated with Ringer's solution and from $17 \pm 1$ to $5 \pm 2 \mathrm{~cm} / \mathrm{sec}$ in the group to be treated with clozapine (Fig. $4 B$ ). Clozapine $(3 \mathrm{mg} / \mathrm{kg}$ ) administered $90 \mathrm{~min}$ after MDMA rapidly increased tail blood flow
(Fig. $4 B$ ), with the increase being sustained so that by the end of the observation period (150 min after MDMA and $60 \mathrm{~min}$ after clozapine), tail flow was $24 \pm 3 \mathrm{~cm} / \mathrm{sec},>8 \pm 1 \mathrm{~cm} / \mathrm{sec}$, the corresponding flow level in Ringer's solution-treated rats, and $>17 \pm 1 \mathrm{~cm} / \mathrm{sec}$, the control level recorded before injection of MDMA (Fig. $4 \mathrm{~B}$ ). MDMA did not change blood flow in the rat superior mesenteric bed (Fig. $4 C)$. Subsequent administration of clozapine slightly increased superior mesenteric flow (Fig. 4C).

\section{Discussion}

Clozapine and olanzapine, atypical antipsychotic agents in clinical use in psychiatry, reverse severe and potentially fatal hyperthermia elicited by MDMA. Reversal of hyperthermia occurs in association with reversal of cutaneous vasoconstriction. Effects of clozapine are dose-dependent. Pedersen and Blessing (2001) demonstrated that the vasoconstricting action of MDMA in rabbits is at least relatively selective for the cutaneous bed; MDMA did not change the resistance of the mesenteric vascular bed. The present study reports similar findings in conscious unrestrained rats, providing the first direct evidence that MDMA constricts the tail vessels in this species, as suggested by Gordon et al. (1991) and Mechan et al. (2002) on the basis of tail temperature recordings, and demonstrates that the vasodilating effects of clozapine are much greater for the cutaneous bed than for the mesenteric bed. Taken in conjunction with the thermoregulatory heatexchanging roles for the ear pinna in rabbits and the tail in rats (Grant et al., 1932; Rand et al., 1965) and with our previous demonstration that cutaneous vasoconstriction contributes to hyperthermia induced by MDMA in rabbits (Pedersen and Blessing, 2001), our present findings suggest that reversal of MDMAelicited cutaneous vasoconstriction contributes to reversal of hyperthermia. Temperature falls after treatment with clozapine or olanzapine at least partially because of transfer of heat to the environment from the dilated cutaneous vascular bed.

\section{Mechanisms whereby clozapine reverses MDMA changes}

Our electrophysiological multifiber recordings of nerve discharge confirm that MDMA causes cutaneous vasoconstriction by activating sympathetic nerves innervating the cutaneous bed, and that clozapine reverses this vasoconstriction by inhibiting neural activity. In a study by Pedersen and Blessing (2001), a unilateral section of the cervical sympathetic trunk (preganglionic sympathetic axons) reduced MDMA-elicited vasoconstriction in the ipsilateral ear pinna. Taken together, our results demonstrate that changes in cutaneous vasoconstriction elicited by MDMA and clozapine occur via effects on CNS neuronal pathways controlling the discharge of preganglionic sympathetic neurons, not via primary peripheral actions.

Pharmacological mechanisms underlying the dose-dependent reversal of MDMA-elicited hyperthermia and cutaneous vasoconstriction by clozapine remain to be elucidated. Body temperature depends on both heat production and heat loss and is therefore a particularly complex variable to study. Presumably, effects on both heat production and heat loss contributed to the reversal of MDMA-induced hyperthermia observed in our study. MDMA increases motor activity (Gordon et al., 1991; Dafters, 1995). Although we did not formally measure this parameter in our study, it was clear that both clozapine and olanzapine substantially reduced the increased motor activity, quieting the animals. Effects on heat production may explain why both olanzapine and clozapine reversed MDMA-elicited hyperthermia to a similar extent, even though the effect of olanzapine on cutaneous blood flow was less marked than that of clozapine. 
MDMA is thought to act by releasing a neurotransmitter from 5-HT, other monoamine neurons, or both or possibly by acting as a direct agonist at 5-HT receptors, dopamine receptors, other monoamine receptors, or a combination thereof (Rattray, 1991; Green et al., 1995; Mechan et al., 2002; Vollenweider et al., 2002). Clozapine, the atypical antipsychotic prototype, and olanzapine, a more commonly used atypical antipsychotic, bind to 5-HT receptors, including 5-HT1A and 5-HT2A subtypes, to dopamine receptors, and to muscarinic receptors, histamine receptors, and $\alpha$-adrenoreceptors (Arnt and Skarsfeldt, 1998; Barnes and Sharp, 1999; Meltzer, 1999). The combination of 5-HT1A receptor agonism and 5-HT2A receptor antagonism is particularly important in the therapeutic actions of atypical antipsychotics (Meltzer, 1999). There is evidence that clozapine can lower body temperature but little consensus concerning mechanisms mediating this affect (Salmi and Ahlenius, 1996, and references therein).

Body temperature can be altered by both 5-HT1A and 5-HT2A receptor mechanisms. Activation of 5-HT1A receptors with specific agonists such as 8 -hydroxy-2-(di-n-propylamino) tetralin (8-OH-DPAT) lowers body temperature (Gudelsky et al., 1986; Cryan et al., 1999). Clearly, 8-OH-DPAT could decrease cutaneous sympathetic nerve activity, thereby increasing cutaneous blood flow and permitting heat loss from the body to the environment. MDMA has been shown to affect dorsal raphe neuronal activity and nociceptive responses via 5-HT1A receptor mechanisms (Millan and Colpaert, 1991; Gartside et al., 1997). Clozapine is an agonist at 5-HT1A receptors (Arnt and Skarsfeldt, 1998), and a 5-HT1A receptor-mediated effect could contribute to the marked sympathoinhibition and vasodilation this agent induces in the cutaneous vascular bed.

Activation of 5-HT2A receptors by direct agonists raises body temperature (Gudelsky et al., 1986; Löscher et al., 1990; MazzolaPomietto et al., 1995). Many hallucinogenic drugs, including indolamines [e.g., lysergic acid diethylamide (LSD)] and phenethylamines (e.g., mescaline), are agonists at 5-HT2A receptors (Aghajanian and Marek, 1999), and these drugs cause hyperthermia in experimental animals, as documented for LSD in rabbits and rats (Horita and Dille, 1954; Murakami and Sakata, 1980). For LSD- and mescaline-like hallucinogens, there is a high correlation between the hallucinogenic dose in humans and the hyperthermic dose in rabbits (Jacob and Lafille, 1963). We recently demonstrated that, as well as causing hyperthermia, the specific 5-HT2A receptor agonist (+/-)1-(2,5-dimethoxy-4-iodophenyl)-2-aminopropane causes marked sympathetically mediated vasoconstriction, selective for the cutaneous vascular bed (Blessing and Seaman, 2003). Thus, activation of 5-HT2A receptors produces hallucinations in humans and increases both body temperature and cutaneous sympathetic nerve activity in experimental animals.

Clozapine and olanzapine, both potent antihallucinogenic agents in humans, have an antagonist action at 5-HT2A receptors (Kehne et al., 1996; Arnt and Skarsfeldt, 1998; Barnes and Sharp, 1999; Meltzer, 1999; Weiner et al., 2001). Clozapine reduces hyperthermia induced by 5-HT agonists (Nash et al., 1988a). Ketanserin, a 5-HT2A antagonist with additional $\alpha 1$-adrenoceptor antagonist properties, also reduces hyperthermia induced by 5-HT agonists (Gudelsky et al., 1986; Löscher et al., 1990; Mazzola-Pomietto et al., 1995), and the drug has been shown to reduce MDMA-induced hyperthermia in rats (Nash et al., 1988b), as well as the modest rise in temperature normally occurring in humans ingesting MDMA (Liechti et al., 2000). MDMA-induced hyperthermia in rats was reduced by the 5-HT2A antagonist $\alpha$-phenyl-1-(2phenylethyl)-4-piperidinemethanol (MDL 11,939) in a study by Schmidt and colleagues (1990). However, Mechan and colleagues (2002) conclude that pretreatment with 5-HT2A receptor antagonists has no substantial effect on MDMA-elicited hyperthermia in rats, although their data do demonstrate that MDL 11,939 did attenuate the hyperthermia, as did MDL R-(+)-a-(2,3-dimethoxyphenyl)-1-[2-(4fluorophenylethyl)]-4-piperidinemethanol (MDL 100,907) at $0.3 \mathrm{mg} /$ $\mathrm{kg}$, a low dose for this selective 5-HT2A antagonist (Kehne et al., 1996). A role for dopamine $\mathrm{D}_{1}$ antagonists in reversal of MDMA-induced hyperthermia was emphasized by Mechan et al. (2002). So far, there is no information concerning the role of 5-HT1A, 5-HT2A, or dopamine $\mathrm{D}_{1}$ receptors in MDMA-elicited cutaneous vasoconstriction.

\section{MDMA and clozapine might alter cutaneous vasomotor tone via bulbospinal sympathetic premotor neurons in the medullary raphe nuclei, via effects at the spinal level, or both} Recent evidence suggests that neurons in the rostral medullary raphe region mediate nociceptive- and temperature-related changes in vasomotor tone in cutaneous vascular beds (Smith et al., 1998; Blessing and Nalivaiko, 2000, 2001; Tanaka et al., 2002). In cats, medullary raphe neurons inhibited by systemically applied 8-OH-DPAT (probably serotonergic cells) increase their discharge when the animal is exposed to cold (Martin-Cora et al., 2000). MDMA could increase cutaneous sympathetic nerve discharge by increasing the activity of these 5-HT bulbospinal neurons, by releasing 5-HT from their spinal terminals, or both, thereby stimulating 5-HT2A receptors on the relevant sympathetic preganglionic neurons. 5-HT excites spinal sympathetic neurons (Coote et al., 1981), but effects on particular receptor and neuronal subclasses are not known. Clozapine, via its 5-HT1A agonist action, could inhibit the discharge of the cutaneous vasomotor bulbospinal 5-HT neurons and, via its 5-HT2A antagonist action, could reverse excitation of spinal cutaneous sympathetic neurons. As noted, the receptor interaction profile of clozapine is complex, and reversal of MDMA-elicited cutaneous vasoconstriction and hyperthermia may occur by presently unsuspected mechanisms.

\section{Psychotropic and cutaneous vasomotor effects of clozapine}

We have documented a close link between the perception of potentially stressful environmental events and sudden falls in cutaneous blood flow (Yu and Blessing, 1997). The cutaneous sympathoinhibitory effects of clozapine may reflect its interaction with common neural circuitry regulating psychological function and cutaneous sympathetic nerve activity (see above discussion of the link between hyperthermia and hallucinations). Cutaneous vasoconstriction also occurs with fever induced by infectious agents or by cytokines (Weinberg et al., 1989) and with hyperthermia associated with heat stroke (Hales, 1997). These conditions may be accompanied by psychological and even psychiatric changes and might also be treatable with clozapine and olanzapine. Well documented physiological actions of atypical antipsychotics have previously been limited to neuroendocrine effects (Nash et al., 1988a), and the lack of robust physiological indices of drug effects has restricted animal studies in the search for new therapeutic agents. Understanding the cutaneous sympathoinhibitory effects of clozapine-like agents may illuminate their antipsychotic actions.

\section{Conclusions}

Clozapine and olanzapine reverse MDMA-elicited cutaneous vasoconstriction and hyperthermia in rabbits. Clozapine reverses MDMA-elicited increases in the discharge of sympathetic nerves supplying the cutaneous vessels, so that cutaneous vasodilatation occurs. Bodenham and Mallick (1996) noted that adequate cutaneous blood flow is important for cooling humans with severe MDMA-elicited hyperthermia, so that treating these patients 
with clozapine or olanzapine could be of significant therapeutic benefit. Elucidating the mechanisms underlying the cutaneous sympathoinhibitory effects of these agents could contribute to our understanding of their antipsychotic actions.

\section{References}

Aghajanian GK, Marek GJ (1999) Serotonin and hallucinogens. Neuropsychopharmacology 21:16S-23S.

Arnt J, Skarsfeldt T (1998) Do novel antipsychotics have similar pharmacological characteristics? A review of the evidence. Neuropsychopharmacology 18:63-101.

Baldessarini RJ, Frankenburg FR (1991) Clozapine. A novel antipsychotic agent. N Engl J Med 324:746-754.

Barnes NM, Sharp T (1999) A review of central 5-HT receptors and their function. Neuropharmacology 38:1083-1152.

Blessing WW, Nalivaiko E (2000) Regional blood flow and nociceptive stimuli in rabbits: patterning by medullary raphe, not ventrolateral medulla. J Physiol (Lond) 524:279-292.

Blessing WW, Nalivaiko E (2001) Raphe magnus/pallidus neurons regulate tail but not mesenteric arterial blood flow in rats. Neuroscience 105:923-929.

Blessing WW, Seaman B (2003) 5-Hydroxytryptamine2A receptors regulate sympathetic nerves constricting the cutaneous vascular bed in rabbits and rats. Neuroscience 117:939-948.

Bodenham AR, Mallick A (1996) New dimensions in toxicology: hyperthermic syndrome following amphetamine derivatives. Intensive Care Med 22:622-664.

Callaway CW, Clark RF (1994) Hyperthermia in psychostimulant overdose. Ann Emerg Med 24:68-76.

Coote JH, Macleod VH, Fleetwood-Walker S, Gilbey MP (1981) The response of individual sympathetic preganglionic neurones to microelectrophoretically applied endogenous monoamines. Brain Res 215:135-145.

Cryan JF, Kelliher P, Kelly JP, Leonard BE (1999) Comparative effects of serotonergic agonists with varying efficacy at the 5-HT(1A) receptor on core body temperature: modification by the selective $5-\mathrm{HT}(1 \mathrm{~A})$ receptor antagonist WAY 100635. J Psychopharmacol 13:278-283.

Dafters RI (1995) Hyperthermia following MDMA administration in rats: effects of ambient temperature, water consumption, and chronic dosing. Physiol Behav 58:877-882.

Garcia JN, Pedersen NP, Nalivaiko E, Blessing WW (2001) Tail artery blood flow measured by chronically implanted Doppler ultrasonic probes in unrestrained conscious rats. J Neurosci Methods 104:209-213.

Gartside SE, McQuade R, Sharp T (1997) Acute effects of 3,4-methylenedioxymethamphetamine (MDMA) on 5-HT cell firing and release: comparison between dorsal and median raphe 5-HT systems. Neuropharmacology 36:1697-1703.

Gordon CJ, Watkinson WP, O'Callaghan JP, Miller DB (1991) Effects of 3,4-methylenedioxymethamphetamine on autonomic thermoregulatory responses of the rat. Pharmacol Biochem Behav 38:339-344.

Grant RT, Bland EF, Camp PD (1932) Observations on the vessels and nerves of the rabbit's ear with special reference to the reaction to cold. Heart 16:69-101.

Green AR, Goodwin GM (1996) Ecstasy and neurodegeneration. BMJ 312:1493-1494.

Green AR, Cross AJ, Goodwin GM (1995) Review of the pharmacology and clinical pharmacology of 3,4-methylenedioxymethamphetamine (MDMA or "Ecstasy"). Psychopharmacology 119:247-260.

Gudelsky GA, Koenig JI, Meltzer HY (1986) Thermoregulatory responses to serotonin (5-HT) receptor stimulation in the rat: evidence for opposing roles of 5-HT2 and 5-HT1A receptors. Neuropharmacology 25:1307-1313.

Hales JR (1997) Hyperthermia and heat illness: pathophysiological implications for avoidance and treatment. Ann NY Acad Sci 813:534-544.

Horita A, Dille J (1954) Pyretogenic effect of lysergic acid diethylamide. Science 120:1100-1101.

Jacob J, Lafille C (1963) Charactérisation et detection pharacologiques des substances hallucinogènes. Arch Int Pharmacodyn 145:528-545.

Kehne JH, Baron BM, Carr AA, Chaney SF, Elands J, Feldman DJ, Frank RA, Van Giersbergen PL, McCloskey TC, Johnson MP, McCarty DR, Poirot M, Senyah Y, Siegel BW, Widmaier C (1996) Preclinical characterization of the potential of the putative atypical antipsychotic MDL 100,907 as a potent 5-HT2A antagonist with a favorable CNS safety profile. J Pharmacol Exp Ther 277:968-981.
Liechti ME, Saur MR, Gamma A, Hell D, Vollenweider FX (2000) Psychological and physiological effects of MDMA ("Ecstasy") after pretreatment with the 5-HT(2) antagonist ketanserin in healthy humans. Neuropsychopharmacology 23:396-404.

Löscher W, Witte U, Fredow G, Ganter M, Bickhardt K (1990) Pharmacodynamic effects of serotonin (5-HT) receptor ligands in pigs: stimulation of 5-HT2 receptors induces malignant hyperthermia. Naunyn Schmiedebergs Arch Pharmacol 341:483-493.

Martin-Cora FJ, Fornal CA, Metzler CW, Jacobs BL (2000) Single-unit responses of serotonergic medullary and pontine raphe neurons to environmental cooling in freely moving cats. Neuroscience 98:301-309.

Mazzola-Pomietto P, Aulakh CS, Wozniak KM, Hill JL, Murphy DL (1995) Evidence that 1-(2,5-dimethoxy-4-iodophenyl)-2-aminopropane (DOI)induced hyperthermia in rats is mediated by stimulation of 5-HT2A receptors. Psychopharmacology (Berl) 117:193-219.

Mechan AO, Esteban B, O'Shea E, Elliott JM, Colado MI, Green AR (2002) The pharmacology of the acute hyperthermic response that follows administration of 3,4-methylenedioxymethamphetamine (MDMA, "ecstasy") to rats. Br J Pharmacol 135:170-180.

Meltzer HY (1999) The role of serotonin in antipsychotic drug action. Neuropsychopharmacology 21:106S-115S.

Millan MJ, Colpaert FC (1991) Methylenedioxymethamphetamine induces spontaneous tail-flicks in the rat via 5-HT1A receptors. Eur J Pharmacol 193:145-152.

Milroy CM (1999) Ten years of “ecstasy.” J R Soc Med 92:68-72.

Murakami N, Sakata Y (1980) A possible role of the serotonergic system in thermoregulation in the rabbit. Neuropharmacology 19:891-895.

Nash JF, Meltzer HY, Gudelsky GA (1988a) Antagonism of serotonin receptor mediated neuroendocrine and temperature responses by atypical neuroleptics in the rat. Eur J Pharmacol 151:463-469.

Nash Jr JF, Meltzer HY, Gudelsky GA (1988b) Elevation of serum prolactin and corticosterone concentrations in the rat after the administration of 3,4methylenedioxymethamphetamine. J Pharmacol Exp Ther 245:873-889.

Ootsuka Y, Rong W, Kishi E, Koganezawa T, Terui N (2002) Rhythmic activities of the sympatho-excitatory neurons in the medulla of rabbits: neurons controlling cutaneous vasomotion. Auton Neurosci 101:48-59.

Owens NC, Ootsuka Y, Kanosue K, McAllen RM (2002) Thermoregulatory control of sympathetic fibres supplying the rat's tail. J Physiol (Lond) 543:849-858.

Pedersen NP, Blessing WW (2001) Cutaneous vasoconstriction contributes to hyperthermia induced by 3,4-methylenedioxymethamphetamine (ecstasy) in conscious rabbits. J Neurosci 21:8648-8654.

Rand RP, Burton AC, Ing T (1965) The tail of the rat, in temperature regulation and acclimatization. Can J Physiol Pharmacol 43:257-267.

Rattray M (1991) Ecstasy: towards an understanding of the biochemical basis of the actions of MDMA. Essays Biochem 26:77-87.

Salmi P, Ahlenius S (1996) Further evidence for clozapine as a dopamine D1 receptor agonist. Eur J Pharmacol 307:27-31.

Schmidt CJ, Black CK, Abbate GM, Taylor VL (1990) Methylenedioxymethamphetamine-induced hyperthermia and neurotoxicity are independently mediated by $5-\mathrm{HT} 2$ receptors. Brain Res 529:85-90.

Smith JE, Jansen AS, Gilbey MP, Loewy AD (1998) CNS cell groups projecting to sympathetic outflow of tail artery: neural circuits involved in heat loss in the rat. Brain Res 786:153-164.

Tanaka M, Nagashima K, McAllen RM, Kanosue K (2002) Role of the medullary raphe in thermoregulatory vasomotor control in rats. J Physiol (Lond) 540:657-664.

Teter CJ, Guthrie SK (2001) A comprehensive review of MDMA and GHB: two common club drugs. Pharmacotherapy 21:1486-1513.

Vollenweider FX, Liechti ME, Gamma A, Greer G, Geyer M (2002) Acute psychological and neurophysiological effects of MDMA in humans. J Psychoactive Drugs 34:171-184.

Weinberg JR, Innes JA, Thomas K, Tooke JE, Guz A (1989) Studies on the circulation in normotensive febrile patients. Q J Exp Physiol 74:301-310.

Weiner DM, Burstein ES, Nash N, Croston GE, Currier EA, Vanover KE, Harvey SC, Donohue E, Hansen HC, Andersson CM, Spalding TA, Gibson DF, Krebs-Thomson K, Powell SB, Geyer MA, Hacksell U, Brann MR (2001) 5-Hydroxytryptamine 2A receptor inverse agonists as antipsychotics. J Pharmacol Exp Ther 299:268-276.

Yu YH, Blessing WW (1997) Cutaneous vasoconstriction in conscious rabbits during alerting responses detected by hippocampal theta-rhythm. Am J Physiol 272:R208-R216. 